\title{
Analysis of Static Excitation System Models for Synchronous Machine
}

\author{
Ravina B. Binnar \\ Electrical Engineering Department \\ Walchand Collage of Engineering \\ Sangli, India
}

\author{
Vijay P. Mohale \\ Electrical Engineering Department \\ Walchand Collage of Engineering \\ Sangli, India
}

\begin{abstract}
Excitation systems can be defined as the system that provides field current to the rotor winding of a generator. Welldesigned excitation systems provide reliability of operation, stability and fast transient response. Excitation systems provide and control the amount of DC current provided by field windings of the generator and this contains all the power controlling and protection components. To fulfill the power demands and desired output characteristics, the excitation system should be configured to match the power system to which the generator is attached. There are two primary aspects of the excitation mechanism: It generates DC voltage (and power) to allow the current through the generator's field windings and it offers a way of controlling the generator's terminal voltage to suit a specified setting point and to provide damping for oscillations in the power system. An aim of the paper is to analyze the two modern static excitation system Viz. ST1A and ST7B from the point of view of their relative performance. The simulation of these models performed in MATLAB SIMULINK environment by considering Single Machine Infinite Bus benchmark incorporated with a hydropower plant model.
\end{abstract}

Index Terms-The Excitation system, MATLAB, Static excitation system, type ST1A, type ST7B, SMIB.

\section{INTRODUCTION}

The excitation system is the crucial part of a synchronous generator. It pumps and regulates dc current to the generator field windings to develop and control the generator voltage. It is imperative to match the performance and capacity of the excitation system to the requirements of the generator and associated electrical network. Synchronous generator excitation system is an integral part of the power grid. A synchronous generator's excitation system allows the power generated by an engine (hydro turbine) to be supplied to the power grid. Consequently, the reliability and availability of excitation equipment is given highest priority while selecting systems. Generators require excitation systems to remain synchronized. The basic function of excitation systems is therefore to provide the energy required for the magnetic field keeping the generator in synchronism. They also affect the

amount of reactive power delivered or absorbed. Constant power factor regulation, AVR and constant reactive power regulation are some control functions that may be applied to excitation systems. In power system stability analyses, when the nature of synchronous machines is to be effectively modeled, it is important to model their excitation systems in precise detail. The required models must be sufficient to reflect the overall performance of the excitation equipment for large, extreme disturbances as well as for minor disturbances. Electricity Generation Authority of Thailand (EGAT) is a government-owned company which is responsible for producing and transmitting electricity across the country. It has different power plant varieties. The hydropower plant in Bhumibol is EGAT's biggest hydropower plant. 8 synchronous generators with total capacity of 779 MW have been installed. The reliability of power plants is closely related to how servicing functions are executed on system appliances. From operation record of power plant between 2002-2006, the unplanned outage hours (UOH) of power plant are changed. UOH's major factor is mostly triggered by power plant excitation device. The $48 \%$ of $\mathrm{UOH}$ is produced by an excitation power failure of 685 hours out of 1,427 hours in total. Hence, to increase the efficiency of the power plant, the maintenance process of the excitation system needs to be reformed.

\section{TYPES OF EXCITATION SYSTEMS}

The system used to give the necessary field current to the synchronous machine's rotor winding is known as an excitation system. In other words the excitation system referred to as the system used to pass current in the field coil and produce the flux. The prime concern of the excitation system is reliability in all service circumstances, simplicity of operation, quick transient response, stability, and maintainability. Types of excitation system based on power source are: Static excitation system, AC excitation system and DC excitation system.

\section{A. DC Excitation System}

DC excitation system consists of the pilot exciter and main exciter The output of exciter is governed by an automatic voltage regulator (AVR). This regulates an alternator's terminal voltage at the output side. The current input of the transformer given to AVR will reduce the current of an alternator during malfunction. When circuit breaker at field gets open, field discharge resistor gets parallel with field winding so that it will discharge potential energy in the highly inductive field winding. The main shaft drives the primary and the pilot exciters or it is driven by motor separately. Exciters which are directly driven are generally favored because they maintain the operating unit system, and the excitation by external disturbances is not excited. The main exciter's voltage rating is around $400 \mathrm{~V}$, and the capacity is around $0.5 \%$ of an alternator's capacity. Due to their high speed, problems in the turbo alternator exciters are very regular and as a standby exciter, separate motor-driven exciters are provided. Fig. 1. displays DC excitation system block diagram. 


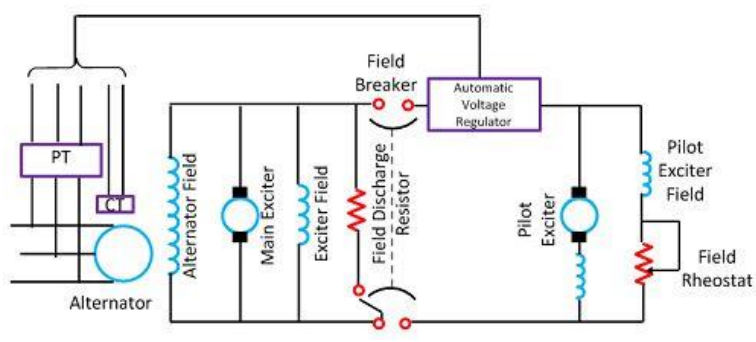

Fig. 1. DC excitation system

\section{B. AC Excitation System}

An alternator is used as source of excitation power to generator. Generally, exciter and turbine generator is kept on shaft. Controlled or diode rectifiers convert exciter's AC output to DC supplied to field of generator. Stationary or rotating rectifiers are used as rectifiers. Types of AC excitation system depends on excitation source, excitation controlling technique, and the type of rectifier. Rotating and stationary rectifier systems are used recently in AC excitation system.

\section{Static Excitation System}

All components in this type of excitation system are static or stationary. The power used for field excitation is extracted from the output terminal of the generator in static excitation system. Excitation transformer is attached to the generator output terminals. The voltage is reduced at the required value around $415 \mathrm{~V} \mathrm{AC}$ by using excitation transformer. A thyristor full bridge rectifier is attached to the transformer output for DC supply. The system is shown as a block diagram which is shown in fig. 2. The thyristor full bridge rectifier's firing angle is governed by the regulator to provide the necessary field excitation. Controller is fed by output terminal of generator to which the secondary terminal of CT and PT are connected. Firing angle is adjusted by output voltage at generator. Let's say, if the terminal voltage of the generator is below its rated value, the current in the field must be increased. Thus, to boost the average value of the field current, the controller reduces the firing angle. Similarly, if the output voltage of generator exceeds its limit, it is adjusted to the required value by using the field current. Average DC current value is reduced by raising the firing angle.

As with the static excitation system, excitation is given on the rotor by field winding wound, thus using slip rings and carbon brushes. The field excitation power comes from the output terminal of the generator so it can only function during much of the generator's normal and steady operation. While starting generator, the output voltage at the generator terminal is zero. So it is impossible to get field excitation with a static excitation system. Separate source of excitation is required in this situation. Once the generator attains its nominal speed, its terminal voltage reaches the nominal voltage and this is why the static excitation system appears in the image. Therefore, as soon as generator exceeds its rated rpm, the battery bank gets separated and the static excitation system feeds the excitation strength. A key benefit of this system is that, the field voltage can be varied very rapidly with the general benefit of generator voltage regulation during temporary fluctuations by an entire range of positive to negative values as needed. There are mainly two types of static exciters, which are presented in this subsection.

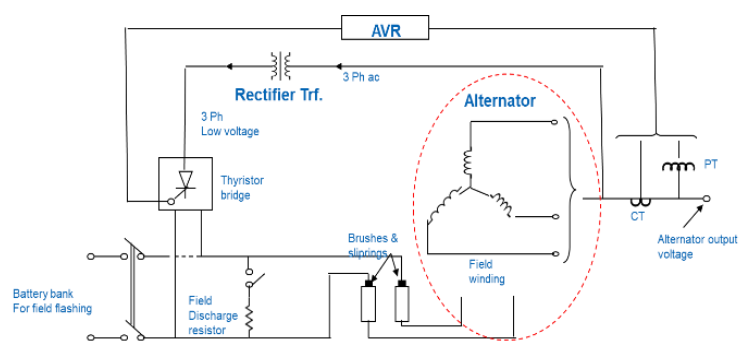

Fig. 2. Schematic diagram of static excitation system

EVOLUTION OF EXCITATION SYSTEM

The development of excitation system in hydroelectric generation unit is given in [6]. The excitation current was previously fed through the rheostat in the generating stations. In the next steps, the pilot exciter generates the strength of the field circuit by rotating or magnetic amplifiers. Network power analyzers which responds faster. The excitation system includes protective components, regulators, controls in a synchronous machine that can provide regulated field current. Excitation system based on SCR provides for static control of output voltage. Automatic voltage regulators which are closed loop excitation control which help to keep the voltage at constant level even when the transmission is disturbed [7,8]. PWM bidirectional power converters, capacitors and controllers are included in excitation system of an induction machine. With the input of generator terminal voltage from sensors, the excitation system in hydro power plant can be controlled and monitored with the help of computer based control [9-12]. Also, reactive and real power is regulated by detecting output current and terminal voltage with network power analyzer [7-8]. The PI back-to-back thyristor controls are incorporated into mini and pico hydropower plants to monitor output voltage and frequency [13]. Two stage converters based on IGBT are designed to provide constant frequency and voltage mounted in distribution generation micro hydro power plants [13-15]. The voltage may also be regulated through the use of an adjustable static excitation device based on solid-state, and so many other voltage control strategies have newly been introduced and discussed in [1517]. Various control techniques used for controlling excitation of synchronous machine is as shown in fig 3 .

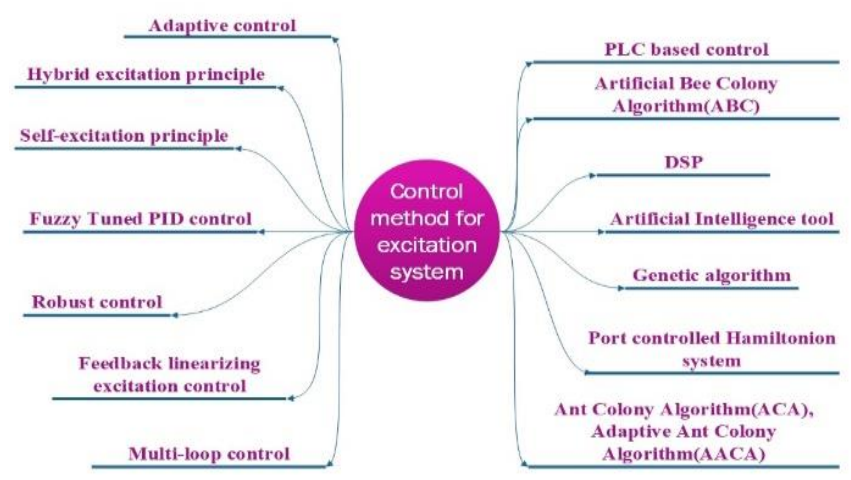

Fig. 3. Various control methods for synchronous machine excitation system 


\section{RESULTS AND DISCUSSION}

The simulation of synchronous machine connected to infinite bus-bar with implementation of static excitation systems is carried out in MATLAB Simulink (2014a). Following are the two implemented excitation systems:

1. Type ST1A excitation system model

2. Type ST7B excitation system model

\section{A. SMIB with type STIA}

Schematic diagram of ST1A Type static excitation system is given in fig. 4 .

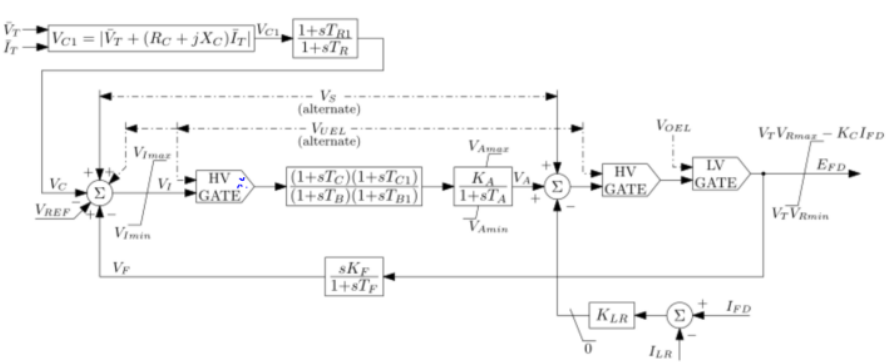

Fig. 4. Type ST1A - Potential-source, controlled-rectifier exciter

With this type of system the excitation voltage is fed back to exciter from the generator terminal (or the unit's auxiliary bus) itself with the use of transformer. This voltage is controlled and rectified using controlled rectifier. The maximum exciter voltage available from these kind of systems relates directly to the terminal voltage of the main generator. Hence, during system-fault conditions causing depressed generator terminal voltage, the exciter ceiling voltage is reduced. The ST1A model provides flexibility to represent series lead-lag or rate feedback stabilization. The exciter ceiling voltage is proportional to the main generators terminal voltage, and the effect of rectifier regulation is represented by KC. Often a field current limiter is used to shield the rotor of generator and the exciter. The limit start setting is defined by ILR and the gain is represented by KLR. Within this model this limiter is defined to ensure compatibility with the reference model ST1A. However, it is possible to disable this limiter by setting KLR to zero. Simulink model of Type ST1A excitation system connected to SMIB is shown in fig. 5.

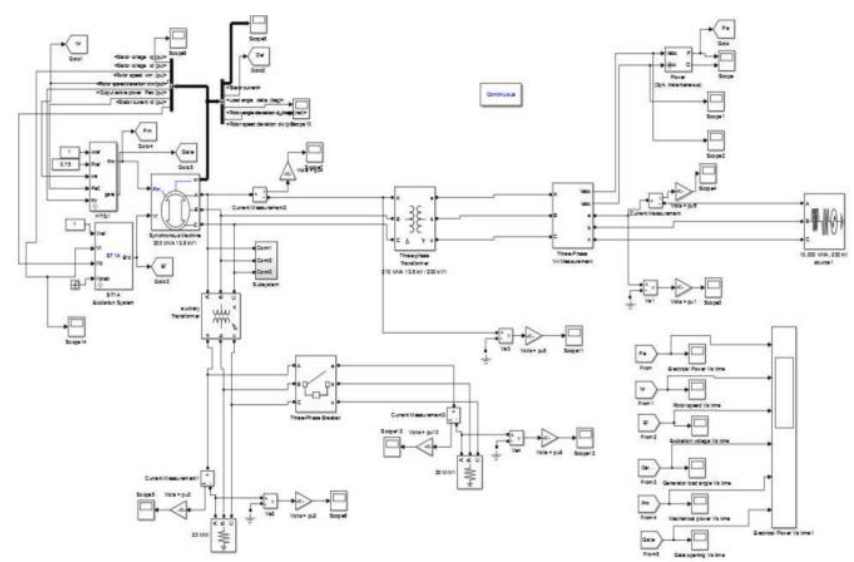

Fig. 5. Simulink diagram of SMIB with type ST1A
The SMIB benchmark system is considered for the simulation of ST1A and ST7B type excitation system. The same set of parameters is used for both excitation systems. The simulation is carried out in MATLAB Simulink environment for time $\mathrm{t}=10 \mathrm{sec}$ and the following results are obtained as shown in fig. 6.

From the obtained simulation results shown below in fig. 6 gives the following observations:

1. The electrical power in transient period oscillates between $-6.5 \mathrm{pu}$ to $+4.55 \mathrm{pu}$ upto $0.8 \mathrm{sec}$. After $0.8 \mathrm{sec}$ the oscillation gradually decreases and system reaches to steady state after $5.0 \mathrm{sec}$.

2. It is observed that speed of rotor oscillates initially for around $3.5 \mathrm{sec}$ and after that it gets settled.

3. Excitation voltage reaches to peak of $+4.8 \mathrm{pu}$ from the initial value of -2.0 pu upto $0.8 \mathrm{sec}$ and oscillates for $4.0 \mathrm{sec}$ and reaches to steady state value after $5 \mathrm{sec}$.

4. The load angle of generator rises from -28 pu to the 58 pu during $0.7 \mathrm{sec}$ and then oscillates for $3.0 \mathrm{sec}$ and attains steady state after $5 \mathrm{sec}$.

5. The mechanical power decreases to 0.73 pu from initial value of $0.75 \mathrm{pu}$ for around $0.2 \mathrm{sec}$ and the it reaches to its peak value of $0.79 \mathrm{pu}$ at time of $0.7 \mathrm{sec}$. It has oscillating period for about $4.5 \mathrm{sec}$. After that it reaches to steady state.

6. Waveform for gate opening settles after $4.0 \mathrm{sec}$ with transient period of $3.0 \mathrm{sec}$.
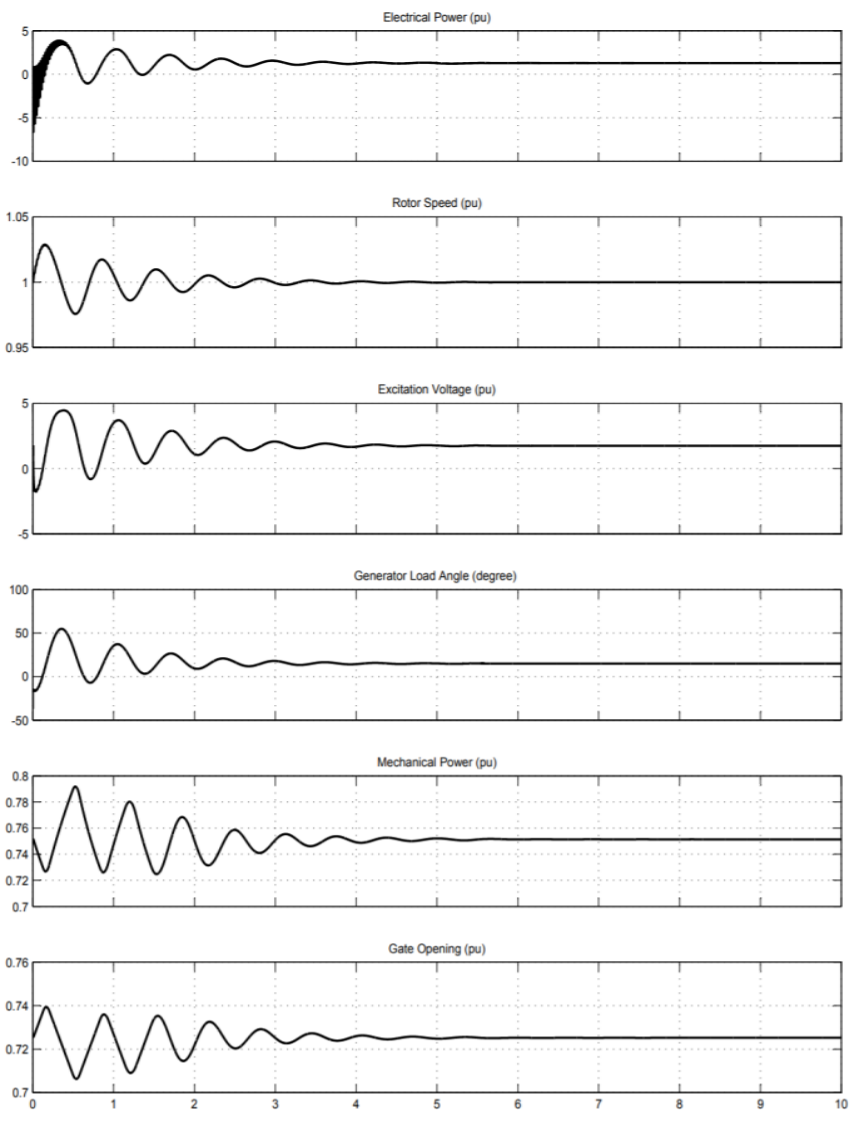

Fig.6. Results of type ST1A excitation system applied to SMIB 


\section{B. $\quad$ SMIB with type $S T 7 B$}

The type ST7B excitation system is a PI controlled system where the lead-lag element can be used to introduce a derivative function (D-action). Schematic diagram of ST7B Type static excitation system is given in fig. 7 .

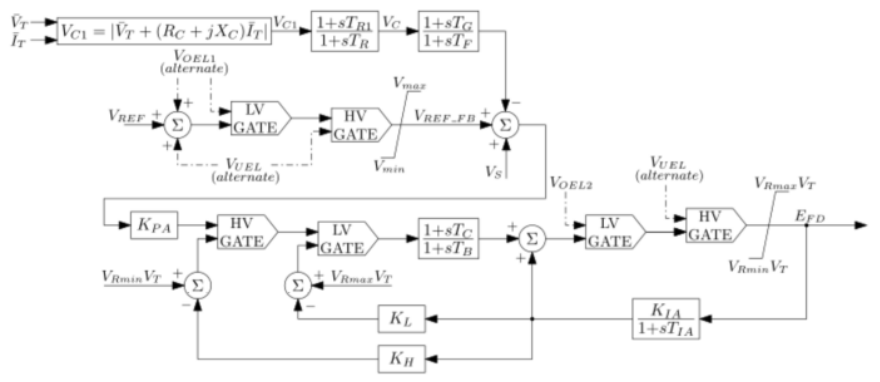

Fig.7. Type ST7B - Potential- or compound-source controlled rectifier exciter

In the similar manner simulation for type ST7B with SMIB is carried out and results obtained are shown in fig. 8.
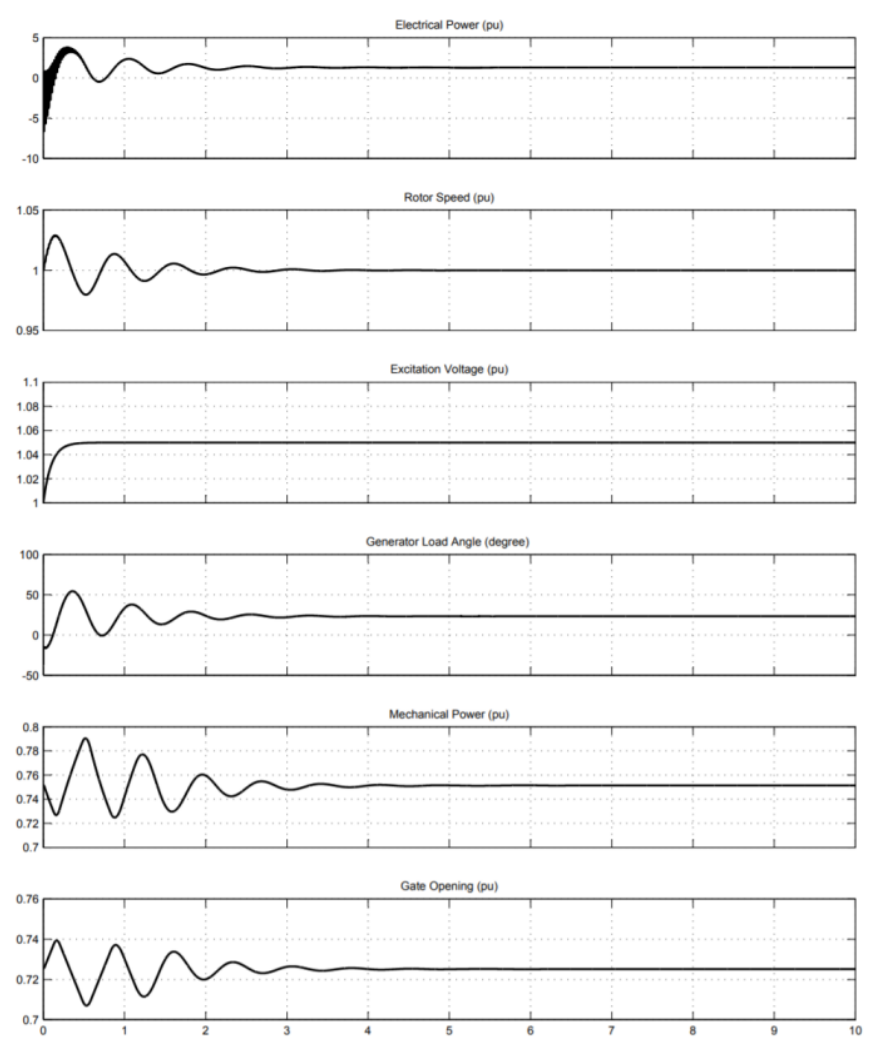

Fig.8. Results of type ST7B excitation system applied to SMIB

From the obtained simulation results shown in fig. 8 using ST7B type excitation system, the following observations are drawn:

1. The electrical power in transient period oscillates between -5.5 pu to +4.62 pu upto $0.8 \mathrm{sec}$. After $0.8 \mathrm{sec}$ the oscillation gradually decreases and system reaches to steady state after $3.0 \mathrm{sec}$.

2. Waveform for rotor speed has its transient period at the initial time for around $2.5 \mathrm{sec}$ and after that it attains steady state.
3. The voltage of exciter does not oscillates around the reference value, it attains its steady state value of 1.05 pu very quickly almost after $0.5 \mathrm{sec}$.

4. The load angle of generator oscillates for $2.0 \mathrm{sec}$ and settles to 0.28 degree after $3.0 \mathrm{sec}$.

5. The mechanical power has transient nature for $2.0 \mathrm{sec}$ and gets the steady state value $0.75 \mathrm{pu}$ after $4.0 \mathrm{sec}$.

6. The gate opening is reduces at the initial state and has oscillating period of around 3.0 seconds and regain its steady state value after $4.0 \mathrm{sec}$.

\section{CONCLUSION}

The simulation of IEEE standard model structures of excitation systems representing synchronous generator is done in MATLAB Simulink 2014a. Excitation system model for synchronous machines is very important to deliver field current and to give protection functions.

SMIB model for type ST1A and ST7B is developed in MATLAB and result analysis is done on it. In this paper, a design scheme of the static excitation system for SMIB power system using ST1A and ST7B is proposed and substantiated by simulation results. It is found that designed ST7B provides good damping enhancement for SMIB power system as compared with conventional excitation model. It is also found that single control structure is enough to damp out all oscillations generated because of various models. The results presented here will assist the excitation users in their selection.

\section{REFERENCES}

[1] Kundur, P., Power System Stability and Control, New York, NY: McGraw-Hill, 1994.

[2] IEEE Power Engineering Society, "IEEE Recommended Practice for Excitation System Models for Power System Stability Studies," IEEE Std. 421.5-2016, 2016.

[3] IEEE Committee Report, "Excitation System Models for Power Systems Stability Studies," IEEE Transactions on Power Apparatus and Systems, vol. PAS-100, pp. 494-509, February 1998.

[4] IEEE Standard Definitions for Excitation System for Synchronous Generator Machines, IEEE Standard 421.1-1986.

[5] IEEE Guide for the preparation of Excitation System Specifications, IEEE Standard 421.4-1987.

[6] Cirstea M, Serban I, Ion C. Marinescu C, Clotea L, "Controlling variable load stand-alone hydro generators", 31st Annual Conference of IEEE Industrial Electronics Society, 2005, IECON2005, pp.25542559.

[7] Zhong Qing-Chang, Kuperman A, Rabinovici $R$, "Time delay compensation in solid-state excited autonomous induction generators", Power Electronics, Machines and Drives, 2004, (PEMD2004), Second International Conference on (Conf.Publ.No.498), vol.2, pp.769774Vol.2,31, March-2April2004.

[8] Jiang GUO, Hongtao Z, Zhihuai X. "Integrated Maintenance Features of Hydro Generator Excitation System", Industrial Electronics and Applications, CIEA 2008,3rd IEEE Conference, pp.2250-2253, 2008.

[9] Guo Jiang, Zeng Hongtao, Xiao Zhihuai, "Real time embedded maintenance system of hydro generator excitation system", Condition Monitoring and Diagnosis, 2008, CMD2008, International Conference on, pp.402-406,21-24 April 2008

[10] Xu Z, Chen Y, Østergaard J., "Security assessment for intentional island operation in modern power system", Elsevire Electric Power Systems Research 2011; vol.81:1849-57.

[11] Prostean G, Biriescu M, et. al "Experimental model of a hydro generator with static excitation", EURO- CON -International Conference on Computer asa Tool(EUROCON), 2011 IEEE, pp.1-4, 2729 April 2011. 
[12] Profumo FMF BC, "A frequency controller for induction generators in stand- by mini hydro power plants," in Electrical Machines and Drives, 1989. Fourth International, pp.256-260.

[13] Are Suul Jon "Variable Speed Pumped Storage Hydro Power Plants for Integration of Wind Power in Isolated Power Systems", Renewable Energy, T J Hammons(Ed.), In Tech (2009).

[14] Pacas M, Molina MG, "Improved power conditioning system of microhydro power plant for distributed generation applications", Industrial Technology (ICIT), 2010 IEEE International Conference on, pp.17331738, 14-17 March 2010.

[15] Amman U, Rees S, "New stator voltage controller for high speed induction machines fed by current source inverters," IEEE 35th Annual Power Electronics Specialists Conference, pp.541-547,2004.

[16] Jovica, Mustafa Kayikci VM, "Dynamic Contribution of DFIG-Based Wind Plants to System Frequency Disturbances", IEEE Transactions on Power Systems 2009; vol.24(no.2):859-67.

[17] Ramirez-scarpetta JM, Saavedra-montes AJ, Malik OP, "Methodology to estimate parameters of an excitation system based on experimental conditions", Electric Power Systems Research 2011; vol.81(no.1):1706. 